\title{
ANÁlise EXPLORATÓRIA dAS ESCALAS DE SILHUETAS BIDIMENSIONAIS E TRIDIMENSIONAIS ADAPTADAS PARA A PESSOA COM CEGUEIRA
}

\author{
EXPLORATORY ANALYSIS OF TWO DIMENSIONAL AND THREE DIMENSIONAL \\ SILHOUETTE SCALES FOR PERSONS WITH BLINDNESS
}

\author{
Fabiane Frota da Rocha MORGADO ${ }^{1}$ \\ Maria Elisa Caputo FERREIRA²
}

\begin{abstract}
RESUM O: Realizar uma análise exploratória da Escala deSil lhuetas Bidimensionais (ESB) eda Escal a deSilhuetas Tridimensionais (EST), verificando qual destas Escalas é a mais apropriada e representativa à pessoa com cegueira congênita. Trata-se de uma pesquisa qualitativa e exploratória. A amostra foi composta por 20 sujeitos adultos com cegueira congênita. Foram entrevistados 10 homens e 10 mulheres, com idades entre 21 e 50 anos, do Instituto Benjamin Constant, no Rio de Janeiro e da Associação dos Cegos de Juiz de Fora, MG. Os Instrumentos para coleta de dados foram: ESB, EST e roteiro de entrevista semiestruturada. A estratégia adotada para tratar os dados foi a A nálise de Conteúdo de Bardin. Foram formadas três grandes categorias: 1) Principais vias de informações sobre o corpo, subdividida em: tato; informações sobre peso e altura; informações das pessoas do convívio; informações culturais; tamanho das roupas e atividade física como referência. 2) Escala de Silhuetas Bidimensionais, subdividida em: não reconhecimento da ESB; dificuldades; utilidades. 3) Escala de Silhuetas Tridimensionais, subdividida em: Reconhecimento da Escala; Relação consigo ou com o outro; Facilidades e preferências da EST. Foi constatado que $90 \%$ dos participantes não reconheceram a ESB, enquanto que todos os participantes reconheceram a EST. A EST é a Escala mais apropriada e representativa para a pessoa com cegueira congênita. Sugere-se a realização de estudos futuros que visem avaliar as qualidades psicométricas da EST.
\end{abstract}

PALA VRA S-CHAVE: imagem corporal; corpo; deficiências da visão.

A BSTRACT: The aim of the study was to conduct an exploratory analysis of the two dimensional and three dimensional Silhouette Scales (2SS and 3SS) so as to determine which one is most suitable and meaningful for persons that are congenitally blind. This is a qualitative and exploratory study. The sample was composed of 20 adult congenitally blind subjects. Ten men and 10 women aged between 21 and 50 years of age from the Benjamin Constant Institute, in Rio de Janeiro and from the Association for the Blind of Juiz de Fora, MG, were interviewed. The tools for the collection of data were: 2SS, 3SS and semi-structured interview guideline. The strategy adopted for data construction was the Content A nalysis of Bardin. Threelarge categories were formed: 1) Main information pathways about the body, subdivided into: touch; information about weight and height; information about the people they live with; cultural information; clothes size, and physical activity as a reference. 2) Two dimensional Silhouette Scale, subdivided into: N on recognition of the 2SS; difficulties; functions. 3) Three dimensional Silhouette Scale: subdivided into: recognition of the Scale; relationship with

\footnotetext{
${ }^{1}$ Doutoranda em Educação Física na linha de pesquisa Atividade Física para pessoas com deficiências, na Universidade Estadual de Campinas. Mestre em Educação Física na linha de pesquisa Aspectos Socioculturais do Movimento Humano, na Universidade Federal de Juiz de Fora (2009). Fez Especialização em Aspectos M etodológicos e Conceituais da Pesquisa Científica pela Universidade Federal de Juiz de Fora (2007). Possui Graduação - Licenciatura Plena em Educação Física - pela Universidade Federal Rural do Rio de Janeiro (2004). . fabi.frm@hotmail.com

2 Professora Adjunto d Universidade Federal de Juiz de Fora e Orientadora nos Programas de Mestrado em Educação Física e em Psicologia. É Pós-doutora (2006) e doutora em Educação pela Universidade de São Paulo (2002). É Mestre em Educação Física pela Universidade Gama Filho (1998) e Mestre em Ciência da Motricidade Humana pela Universidade Castelo Branco (1996). É graduada em Educação Física pela Universidade Federal de Juiz de Fora (1993) e em Serviço Social pela Faculdade de Serviço Social do Rio de Janeiro (1977). caputoferreira@terra.com.br
} 
oneself or with others, ease and preferences of the 3SS. It was found that $90 \%$ of the participants did not recognize the 2SS whileall of the participants recognized the 3SS. The 3SS is the more adequateand meaningful scale for the congenitally blind. Further studies aiming to assess the psychometric qualities of the 355 are needed.

KEYWORDS: Body Image; Body; Visual Impairments.

\section{INTRODUÇão}

Este artigo refere-se à parte de um estudo maior que visa discutir a avaliação da imagem corporal da pessoa com cegueira congênita e propor alternativas metodológicas para tal. A imagem corporal pode ser considerada a forma específica e singular em que o sujeito constrói a representação mental de seu corpo existencial, ou seja, de sua identidade corporal. Ela não deve ser confundida com uma figuração unicamente visual do corpo, pois trata-se de uma representação mental bem mais abrangente e complexa do quesi mplesmente uma imagem visual (CASH , 2004; KRUEGER, 2004; SCHILDER, 1999; TA VARES, 2003).

A imagem corporal do sujeito com deficiência visual possui particularidades, o que a torna apenas diferente dos indivíduos que enxergam, sem perder sua significância. Isto porque Schilder (1999) considera que a visão possui papel preponderante na formulação da imagem corporal. As qualidades visuais de um fenômeno ou objeto são importantes atrativos para queo indivíduo experimente relações com o meio. Dessa forma, a visão é um importante orifício simbólico ${ }^{3}$, que possibilita a entrada de diferentes informações, sobretudo do corpo, em sua relação ativa com o mundo e, consequentemente, atua na estruturação da imagem corporal.

Entretanto, cumpre esclarecer que "precisamos do corpo para ver, mas não apenas em função da experiência específica da visão" (SCHILDER,1999, p. 109). Há uma simetria e um equilíbrio interno da imagem corporal, o que torna perigosa a valorização excessiva de apenas uma parte dela. O que deve ser valorizado é um aspecto multifacetado para a estruturação final dessa imagem, já que, nela, atuam diferentes estruturas sensórias e perceptivas, as quais permitem a formulação de uma representação mental. A demais, há influência das dimensões fisiológicas, sociológicas e libidinais, que não possuem a visão como um fator preponderante para o desenvolvimento da imagem corporal. Logo, a imagem do corpo é própria do sujeito histórico e existencial, em sua constanteinteração com o

\footnotetext{
${ }^{3}$ Para Schilder (1999), os orifícios simbólicos são considerados estruturas corporais que possibilitam um contato mais íntimo do indivíduo com o mundo. Nas palavras deste autor, os orifícios são "as partes mais importantes de nosso corpo" (p. 97), pois através deles "ingerimos o ar, alimento e produtos sexuais; por meio deles ejetamos urina, produtos sexuais, fezes e ar" (p. 139). Em destaque, Schilder (1999) afirma quea visão é um importante orifício simbólico, visto que "os olhos são, ao menos simbolicamente, um órgão receptor, e seu papel simbólico [...] se relaciona intimamente com esta função de orifício simbólico através do qual o mundo nos penetra" (p. 139).
} 
mundo, sentindo-o, reconhecendo-o e, principalmente, percebendo-o, o que torna possível ao sujeito que não enxerga formular sua imagem corporal.

Frente ao exposto, qual seria o instrumento tátil mais apropriado e representativo para avaliar a imagem corporal do indivíduo com cegueira? A literatura recomenda quesejam feitas adaptações bidimensionais etridimensionais para serem utilizadas como recursos queauxiliem a construção deimagens mentais pelas pessoas com deficiência da visão (BATISTA, 2005; LAPLANE; BATISTA, 2003; NUNES, 2004; ORMELEZI, 2000). A tarefa em relação a este grupo é a de buscar as mel hores formas de representação e os materiais mais adequados.

A linguagem bidimensional ou grafo-tátil é uma representação em alto-relevo, sem a representação de profundidade, muito utilizada para a adaptação de figuras, letras, numerais esímbolos em uma leitura acessível à pessoa com deficiência visual. Ela exige um elevado grau de abstração da realidade. A linguagem tridimensional é aquela representada em forma de maquete ou mi niatura. Ela podeser entendida como uma acessível forma de “visão" do mundo pelo indivíduo com cegueira e um eficiente meio de representação gráfica, tendo em vista que o modelo em forma de maquete possui características de extensão e profundidade semelhantes e condizentes com a realidade, dado que esta é tridimensional.

A insatisfação, por sua vez, é um componente atitudinal da imagem corporal. Ela é definida como uma alteração cognitivo-emocional (GARNER; GARFINKEL, 1981). A insatisfação com o corpo pode levar ao desenvolvimento de uma imagem corporal negativa, que diz respeito a um desgosto profundo com o corpo (CASH, 2004). Dessa forma, é relevante o desenvolvimento de estudos e pesquisas que se propõem rastrear traços de insatisfação corporal no público com cegueira. Todavia, para tal, énecessário um instrumento de avaliação desta al teração apropriado a este público, ou seja, que realmente represente a ele aquilo que se pretende com seu uso.

Já existem, no Brasil, duas Escalas que foram adaptadas e criadas com o propósito de avaliar a insatisfação corporal da pessoa com cegueira congênita: Escala de Silhuetas Bidimensionais - ESB - ea Escal a deSilhuetas Tridimensionais - EST (MORGADO; FERREIRA, 2009). Tais Escalas seguiram a sequência de silhuetas proposta na Escala de Stunkard, Sorensen e Schlusinger (1983), comumente utilizada na literatura da imagem corporal (MORGADO et al. 2009). Vale lembrar que as Escalas adaptadas e criadas no Brasil ainda não foram exploradas por um público representativo de pessoas com deficiência visual.

Este estudo objetiva realizar uma análise exploratória da Escala de Silhuetas Bidimensionais e da Escal a de Silhuetas Tridimensionais, verificando qual destas Escalas é a mais apropriada e representativa à pessoa com cegueira congênita. 


\section{Metodologia}

Esta é uma pesquisa qualitativa e exploratória. Malhotra (2001) considera quea pesquisa qualitativa éa principal metodologia utilizada nos estudos exploratórios. A pesquisa exploratória, por sua vez, possui capacidadedeexaminar um problema de investigação pouco estudado ou que não tenha sido abordado antes (SAMPIERI; COLLADO; LUCIO, 1991).

\section{Instituições}

Foram sel ecionadas duas instituições: Instituto Benjamin Constant (IBC) e Associação dos Cegos de Juiz de Fora, por responder aos seguintes critérios: o IBC é referência nacional no atendimento às pessoas com deficiência visual e a Associação dos Cegos é referência no Estado de Minas Gerais; elas possuem diferentes contextos culturais e concentram um número relevante de sujeitos com cegueira.

\section{População e A mostra}

A população foi composta por sujeitos adultos com cegueira congênita. Foram consideradas pessoas com cegueira os indivíduos que apresentam desde ausência total devisão até a perda da percepção lumi nosa eque terão de fazer uso do Sistema Braille para o processo de ensino e aprendizagem (FERREIRA, 2007). Foram considerados congênitos os indivíduos que nasceram com cegueira ou a adquiriram até os cinco anos de idade (ALMEIDA, 1995; LEMOS, 1981). A amostra foi composta por 20 sujeitos adultos, com idades entre 21 e 50 anos, sendo 10 homens e 10 mulheres, com cegueira congênita, da Associação dos Cegos de Juiz de Fora, MG edo IBC, no Rio deJaneiro, RJ. Em cada uma das Instituições, foram recrutados 10 sujeitos.

Os parâmetros para o cálculo do tamanho da amostra seguiram as orientações de M al hotra (2001). Este autor aponta que, em fases exploratórias e de préteste, a população deve ser pequena, de 5 a 10 entrevistados, mas pode crescer na medida em que as entrevistas se sucedem. Dessa forma, se os resultados se apresentarem similares a partir da 5 a entrevista, pode-se entender como um ponto de saturação, ou seja, que já éo suficiente para responder aos objetivos do estudo. Portanto, o tamanho exato da amostra deve ser suficiente para garantir a similaridadee variedade da população e oferecer uma visão crítica do instrumento.

Três critérios nortearam a inclusão dos sujeitos: manifestar diagnóstico de cegueira congênita fornecido pelas Instituições selecionadas; não possuir outras deficiências associadas, conforme constar no diagnóstico analisado e possuir, ou já ter possuído, vínculo Institucional, não sendo necessário residir no local. Três critérios de exclusão foram adotados: manifestar al gum distúrbio mental; estar ausente no dia da coleta de dados e recusar participar, livremente, da pesquisa. 
Este estudo responde aos parâmetros éticos de pesquisa ${ }^{4}$. Todos os participantes assi naram o Termo de Consentimento Livree Esclarecido (TCLE). A assinatura foi feita através da impressão digital por aqueles quenão aprenderama assinar o nome com "tinta". O TCLE foi disponibilizado em Braille, porém, aos sujeitos que não dominam esse código, foi oferecida a informação oral, sempre com a presença de uma testemunha.

\section{Instrumentos}

Os Instrumentos para coleta de dados foram a ESB (Figura 1); EST (Figura 2); roteiro de entrevista semiestruturada e gravador digital para gravação e transcrição dos relatos. O roteiro de entrevista era composto pelas seguintes perguntas: a) A o observar a ESB, o que você reconhece? b) Há diferenças entre as figuras? Sehouver, quais vocêidentifica? c) Vocêacredita quesepareça com al guma figura numerada de 1 a 9? Qual? d) A o observar a EST, o que você reconhece? e) Há diferenças entre os bonecos? Se houver, quais você identifica? f) Você acredita que se pareça com al gum boneco numerado de 1 a 9? Qual? g) Em qual das Escalas (ESB ou EST) vocêachou mais fácil o reconhecimento? Por que? h) Como vocêfaz imagem de seu corpo?

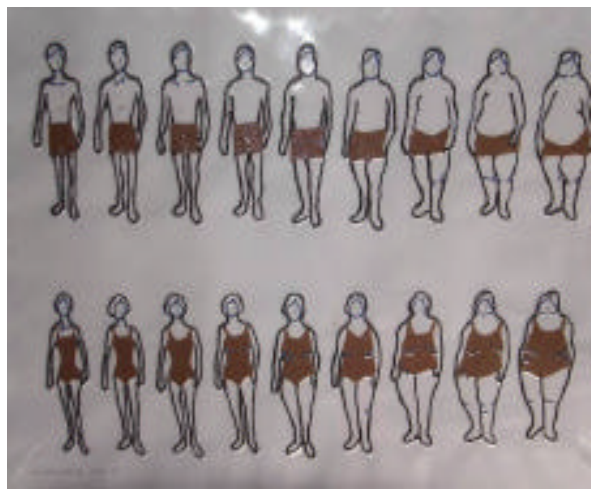

Figura 1: Escala de Silhuetas Bidimensionais

Fonte: $\mathrm{O}$ autor (2008).

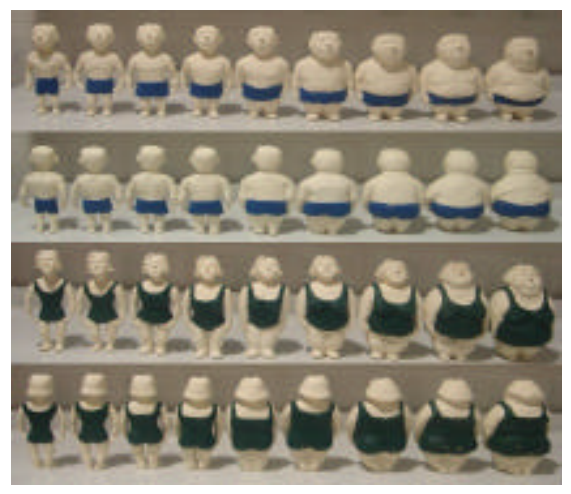

Figura 2: Escala de Silhuetas Tridimensionais

Fonte: O autor (2008).

Coleta de dados

Foi aplicada a entrevista semiestruturada e solicitada a autorização dos participantes para a gravação desta, que foi transcrita na íntegra para posterior análise. A aplicação da entrevista foi feita mediante exposição das duas Escalas

\footnotetext{
${ }^{4} \mathrm{O}$ projeto relativo a este estudo foi aprovado pelo Comitê de Ética em Pesquisa da Universidade Federal de Juiz de Fora (CEP/ UFJF) no dia 18 de dezembro de 2008, conforme Parecer nº. 423/ 2008 e Relatório nº. 1619.309.2008. Está inscrito no Sistema N acional de Ética em Pesquisa (SISNEP) sob o número 222266).
} 
adaptadas, a ESB e a EST. Os participantes ficaram sentados à mesa e sobre esta foi apresentada uma Escala de cada vez. Eles começaram explorando a ESB, quando responderam às perguntas sobreesta. Em seguida, foi recolhido o primeiro exemplar e, então, a EST foi apresentada para que pudessem explorá-la eresponder às perguntas da entrevista.

\section{A nálise dos dados}

A estratégia adotada para tratar as entrevistas foi a A nálise de Conteúdo. Para Bardin (1977), essa análise trata-se deum conjunto de técnicas que analisam as comunicações e visam obter, por meio de procedimentos sistemáticos eobjetivos de descrição do conteúdo das mensagens, indicadores - quantitativose qualitativos - que permi tam a inferência de conhecimentos relativos às condições deprodução erecepção dessas mensagens. N esteestudo, o conteúdo das entrevistas foi analisado com a técnica de formação de categorias, que permiteao pesquisador inferir algumas informações, destacando as que apareceram repetidas vezes em situações distintas, tornando possível uma análise exploratória do fenômeno.

\section{Resultados e discussões}

Este estudo aponta para a formação de três grandes categorias, que se mostraram relevantes no discurso dos sujeitos analisados. A primeira delas, chamada "principais vias de informações sobre o corpo", refere-se às estratégias utilizadas pelos participantes para obter informações de seu corpo e estruturar sua imagem corporal. Embora esta categoria não seja uma resposta para o principal objetivo deste estudo, ela é relevante para contextualizar a formação da imagem corporal do sujeito com cegueira congênita. A segunda categoria destacada foi a "Escala de Silhuetas Bidimensionais" (ESB) e a terceira, a "Escala de Silhuetas Tridimensionais" (EST), ambas relacionadas às informações sobre a representação queas Escal as exploradas nesteestudo possuem para os participantes. Em seguida, a discussão de tais categorias.

\section{Principais vias de informações sobre o corpo}

Na ausência do estímulo visual, os sujeitos com cegueira reorganizam outras vias sensórias capazes de lhes trazer informações preciosas sobrea imagem formada de seu corpo, pois, nessa imagem, o fator preponderante não é a função específica do estímulo visual, mas a organização de outras fontes sensitivas (SCHILDER, 1999; DOLTO, 2001; DOLTO e NASIO, 2008). Dentre tais fontes, destacaram-se neste estudo seis subcategorias, quais sejam:

a) Tato: refere-se às justificativas utilizadas que vinculam o conhecimento do próprio corpo ou de algum aspecto dele ao uso específico da esfera tátil. 
b) Informações sobre peso e altura: refere-se às justificativas que utilizam o conhecimento do próprio peso eda própria al tura para obtenção deinferências relativas às formas e dimensões corporais.

c) Informações das pessoas do convívio: sintetiza justificativas apresentadas acerca da importância das informações oriundas dos pais, professores e pessoas do convívio em geral para traçar subsídios teóricos que auxiliarão na formação de imagens do próprio corpo e do meio, especialmente, na concretização de conceitos abstratos.

d) Informações culturais: refere-se às interpretações do participante sobre os aspectos que cercam os ideais de corpo da cultura a qual faz parte, sendo possível um parâmetro de comparação entre o próprio corpo e tais ideais.

e) Tamanho das roupas: refere-se aos relatos que associam a dimensão da roupa com a dimensão do próprio corpo.

f) A tividade física como referência: refere-se às justificativas que vinculam a atividade física às referências sobre o próprio corpo, como exemplo, musculatura mais firme e formas corporais mais definidas.

N a sequência, apresenta-sea análise dos dados referentes a essas seis subcategorias relatadas. A começar pela análise da via de informação relatada por $65 \%$ dos participantes como principal via sensitiva para a pessoa com cegueira: o tato.

Merleau-Ponty (2007, p. 131) demonstra que uma associação harmônica entre o estímul o físico eas qualidades do sensível, princi palmente do tátil, permite o espetáculo do visível, mesmo nos indivíduos desprovidos da visão. O tato constitui um sistema sensorial que possui determinadas características imprescindíveis ao indivíduo que nunca enxergou, pois permite a captação de diferentes propriedades físi cas dos objetos, tais como forma, textura, temperatura e relações espaciais, bem como diferentes informações oriundas do próprio corpo, como relata a participante 15:

[...] se eu colocar o brinco eu vou perceber que tem um carocinho, aqui, no lugar que eu vou col ocar o brinco tem uma coisa diferente, então, édetal hes quea gentevai observando, que a gente tem que observar com o dedo, com o toque de mão, com a mão [sic].

Entretanto, cumpre ressaltar que são propriedades adquiridas ao alcance da mão, o que difere da visão biológica, que permite a obtenção de informações simultâneas emultidimensionais, como afirma a mesma participante:

[...] agora, muitas coisas a mão não funciona, nem tudo! Por exemplo, eu vou pegar uma roupa, eu vou saber que ela não tá amarrotada, que ela não tá rasgada, agora, se ela tiver uma roupa manchada, eu não vou saber. Tem coisa que você tem que ter auxílio, eu pedi auxílio, porque seeu for num lugar e pegar aquela roupa enão observar, eu vou pegar ela e vestir de frente para trás [sic]. 
Dessa forma, pode-se inferir que o tato não é um substituto direto da visão, mas uma possibilidade de formação de imagens mentais pelos indivíduos com cegueira. A participante $16 \mathrm{fez}$ uma associação entre o olho do cego e sua mão: "E u formo a imagem tocan do em mim, com as próprias mãos, porque o ol ho de quem nunca viu, o ol ho do cego que nunca enxergou é a mão, o ol ho da gente é a mão". Esta afirmação vai ao encontro da teoria deDolto eN asio (2008), autores queconsideram que as pessoas privadas de um parâmetro sensorial têm de reorganizar a simbolização dos outros parâmetros sensitivos. Eles apontam que crianças cegas, ao projetarem esculturas, tendem a modelar o tamanho das mãos muito mai or que nas modelagens das crianças que veem. Isso por um motivo muito claro, segundo os autores: é com as mãos que o cego vê, é nas mãos que ele tem olhos.

O filósofo Merleau-Ponty (2007) defende a idéia de que a relação do sujeito com o mundo, durante toda sua existência, é fundamental para a visão, pois todo visível é moldado no sensível, dessa forma, o que for considerado tátil pode estar voltado de alguma maneira à visibilidade. As pessoas com cegueira formam imagens daquilo que puderam experimentar durantesua vida, dessa forma, o contato com o próprio corpo éfundamental para seu reconhecimento, como afirma a participante 19, ao ser perguntada como ela fazia a imagem de seu corpo:

\footnotetext{
A gente põe a mão no corpo da gente, a gente toma banho, se arruma, passa creme ou passa talco. Eu brinco comigo muito, eu brinco com as minhas pernas, eu brinco com os meus braços, eu faço massagem na barriga.
}

Embora o tato tenha aparecido com mais força nos depoimentos analisados, visto quea maioria, ou seja, $65 \%$ dos participantes, afirmou queeleéa principal via que traz informações sobre o corpo, o peso e a altura apareceram como mais uma fonte de referências, como consta no seguinte discurso: "E u sei que sou magro por cau sa da relação peso eal tura, aí éuma coisa mais lógica mesmo. Entendeu?" $(p 2)^{5}$. Além disso, o outro, na figura de um familiar, principalmente a mãe, o professor ou qualquer pessoa que interaja com a pessoa acometida pela cegueira é fundamental para Ihe oferecer informações associativas em sua representação mental (DOLTO, 2001). Como exemplo, destacam-se os depoimentos dos participantes 18 e 15 :

\footnotetext{
[...] P orque a minha mãe sempre falava qual é os loiro lá da minha casa, os ol hos azul. [...] quando a gente era pequeno, a minha mãe ia falando com a gente assim, ela ia falando as coisa, aí a gente foi aprendendo a observar o corpo da gente (p18) [sic].

[...] E quando a gente estudava, também, na escola, tinha aula, tinha E ducação Física, a gentenão pratica, eu não pratico E du cação Física, mas na escola tinha professora, ela dava aula especializada, então, ela explicava pra gente as coisas (p15).
}

Dessa forma, as pessoas do convívio do indivíduo com cegueira podem possibilitar, ainda, associações de termos abstratos como cor da pele e cores em

\footnotetext{
${ }^{5} \mathrm{~A}$ letra "p" que aparece ao final das falas refere-se à "participante". 
geral, por exemplo: "Eles falam que sou clarinha, né. Sou branquinha. Eles falam também que sou assim... gordinha, né. [Eles quem?] 0 povo, o pessoal daqui mermo, ué.." (p13). Em outro depoimento:

A h, aí as pessoas que me falam, através das informações, as pessoas falam pra gente. [...] Vermelho... I gual o pai passa pra gente é uma cor mais escura, igual a que eles falam vermelho, fogo, né, essas coisas todas que eles falam. A gente aprende a definir coisas através do que foi passado pra gente (p17).

Dolto (2001) afirma que um cego de nascença pode fal ar palavras que tomarão para ele sentido diferente daquele de uma pessoa que enxerga. Mesmo que um indivíduo cego nunca tenha enxergado uma cor, por exemplo, ele podetêla representado em sua imaginação, pois ele já ouviu as pessoas falarem sobreelas efazerem associações com estímulos térmicos como cores frias equentes. Elepode fazer, também, uma representação auditiva eemocional das cores. No que se refere à imagem corporal, os indivíduos com cegueira reorganizam a simbolização de outras vias perceptivas para o seu desenvolvimento, utilizando, ainda, as informações obtidas por meio da cul tura na qual el es se encontram inseridos, como afirma a participante 3 :

A cultura diz... em partes assim, se fosse para uma modelo, eu jamais poderia ser (risos), porque aí eu já estou acima do peso, mas, sepensar no padrão de bel eza cultural, digamos que eu esteja dentro dele, porque eu não estou gorda, estou magra, não estou magricela, estou média também [sic].

A cultura pode ser entendida como um conjunto de estruturas psicológicas por meio das quais o indivíduo ou grupo de indivíduos guia seu comportamento (GEERTZ, 1989). O depoimento anterior revela que, embora a partici pante nunca tenha visto a imagem de um corpo, el a é consciente dos ideais de corpo belo que permeiam a atual cultura, visto que seu relato vai ao encontro da afirmação de Jackson (2004), o qual pontua que as culturas ocidentais contemporâneas idealizam uma silhueta magra para as mulheres. Portanto, observa-se que as informações que transitam na cultura são importantes fontes de conhecimento sobre o próprio corpo e o corpo do outro e atuam na formulação da imagem corporal, como já afirmava Schilder (1999).

Além da cultura, o tamanho da roupa é referência deinformações sobre o corpo para a pessoa com cegueira, como afirma o participante 15:

A questão de a gente engordar e emagrecer, a gente que é deficiente visual, uma das coisas que a gente deve prestar muita atenção é nas roupas. [...] Porque se a gente engorda, a roupa aperta, se emagrece, vai folgar. Então, eu acho, assim, uma das maneiras mais práticas do deficiente visual ver quando ele engordou ou emagreceu é pelas roupas.

Schilder (1999) esclarece que qualquer coisa que participe do movimento consciente do corpo é acrescentada à imagem que a pessoa faz de si, 
tornando-se parte dela. Dessa forma, as roupas, os acessórios, uma bengala ou o alimento que o indivíduo ingere são incorporados em sua imagem, além da dor orgânica ou psicogênica e dos excrementos do corpo, mesmo nos momentos seguintes em que estão dissociados dele. No caso específico das roupas, elas apareceram nos discursos como referência para que o indivíduo reconheça mudanças físicas no seu corpo, na medida em que elas podem trazer sensações de frouxidão ou aperto, quepossuem siginificados específicos ao sujeito com cegueira. Assim como as roupas, a atividade física aparece como referência:

\footnotetext{
Q uando eu fazia A tletismo, eu acho que eu tinha a perna mais grossa ainda, era mais grossa, aí eu parei, aí foi ficando mais fina, etal. Quando eu estava praticando esporte do A tletismo eu tinha a musculatura maneira, tipo... 0 músculo era mais firme (p8).

Por eu fazer alguma atividade física, meu corpo sempre foi assim, mais magro, desde criança, sabe? (p16).
}

N estes relatos, destaca-sea associação queos participantes fizeram entre atividadefísica, corpo magro e musculatura firme. Já se sabe que a atividade física pode trazer ao indivíduo diferentes benefícios físicos, mas o que é relevante neste estudo é que ela aparece como facilitadora da formulação da imagem do corpo, o quevai ao encontro das afirmações de Schilder (1999). Para esteautor, o movimento possui papel preponderante no desenvolvimento pleno da imagem corporal, na medida em que pode propiciar sensações novas ediferenciadas daquel as adquiridas em estado de repouso, por conseguinte, pode auxiliar na unificação das partes corporais e no reconhecimento do próprio corpo. Através da atividade física o indivíduo mantém um contato com o mundo exterior e com os objetos, o que favorece inúmeras impressões relativas a seu corpo. Essas experiências corporais podem proporcionar o tensionamento ou o relaxamento dos músculos, portanto, uma imensa influência na imagem corporal.

Para sujeitos que não enxergam, a produção de imagens é singular, baseada em sua forma específica de ver o mundo e se relacionar com ele. Nesta pesquisa, destaca-se que a formulação da imagem corporal da pessoa com cegueira possui como principais pontos de referência o tato, as informações sobrepeso eal tura, informações das pessoas do convívio, informações culturais, o tamanho das roupas ea atividadefísica. Dentretais informações, o tato sedestaca como a via de informação sobre o corpo mais citada e enfatizada pel os participantes, portanto, pode-se inferir queeletambém seja o responsável por trazer informações sobre as coisas eos objetos que cercam o sujeito com cegueira. N o caso específico deste estudo, os participantes fizeram uso da esfera tátil para explorar a ESB e EST. As categorias que seguem referem-se à representação destas Escalas para os participantes.

\section{Escala de Silhuetas Bidimensionais}

Preisler (1997) e Laplane e Batista (2008) privilegiam e recomendam a utilização de materiais adaptados para o processo de formação de conceitos do 
sujeito que não enxerga. Os autores entendem que devem ser oferecidos ao cego denascença recursos que propiciem diferentes atividades. Entretanto, há influência das diferenças individuais na trajetória de vida de cada pessoa com cegueira, que irá distinguir o modo de lidar com a deficiência e seus efeitos na construção da identidade. Por conseguinte, haverá distinção entre aqueles sujeitos que irão reconhecer determinado recurso e os que não irão reconhecer o mesmo. Dessa forma, o tipo de recurso a ser adotado deve responder a necessidade, interesse e objetivos próprios de cada sujeito.

Nesse estudo, dada a necessidade de traçar linhas gerais sobre o reconhecimento da ESB, fez-se uso dos depoimentos dos participantes quanto à identificação da mesma. Tais depoimentos foram agrupados em três subcategorias:

a) Não reconhecimento da ESB: refere-se às justificativas que confirmam a não identificação das figuras constituintes da ESB.

b) $\mathrm{D}$ ificuldades: sintetiza as principais dificuldades encontradas pelas pessoas com cegueira para a identificação da ESB.

c) U tilidades: refere-se aos depoimentos que afirmam alguma utilidade da linguagem grafo-tátil, apesar da dificuldade de percepção tátil.

Em seguida, apresenta-se a análise das três subcategorias relatadas.

Indubitavel mente, a maioria dos participantes - 90\% - não reconheceu de imediato as formas humanas representadas na ESB, assim como não reconheceu as diferenças nas dimensões corporais dos bonecos. Os model os tornaram-se um "jogo de adivinhação", no qual os participantes tiveram a intrincada tarefa de adivinhar o que as figuras representavam. Tarefa considerada difícil e cansativa pel os sujeitos, logo, de complexa identificação, o que os obrigava a arriscar al guns conceitos sobre o que estava desenhado. Um dos conceitos foi relacionado a uma tesoura, como afirma o participante 4: "Isso aqui pra mim poderia ser uma tesoura, uma tesoura entre aberta, entendeu? Eu misturei um com o outro, porque para mim isso aqui era uma parte da tesoura e isso daqui era a outra parte da tesoura, segundo a minha interpretação". Em outro momento, o mesmo participante relatou que os braços dos bonecos se confundiam com palitinhos:

Por exemplo, aqui, ó, esse braço está juntíssimo do corpo, então, tipo assim, o que eu posso reparar no braço? Q ue são dois palitinhos, a única coisa que eu posso dizer do braço é que são dois palitinhos. (p4).

Destaca-se, ainda, um participantequeconfundiu os desenhos daEscala com dedos: "A h, são iguais, né? Parecidos, isso aqui são dedos?" (p9). Ou ainda com um quadrado, mapa eboca, ao mesmo tempo: “D esenhos, né? É uma figura, né? [...] Parece um quadrado. Parece um mapa, não parece? E aqui (os pés)... parece uma boca! Sei lá o que é isso." (p13). Teve partici panteque relacionou a ESB com vegetações como plantas e raízes: "I sso aqui dá a impressão que é uma planta, aqui embaixo, oh. P el o jeito das raízes, oh, raízes de plantas." (p18). 
As dificuldades encontradas pelos participantes deste estudo, no que tange à identificação das figuras bidimensionais da ESB, vão ao encontro das afirmações já pontuadas na literatura (ORMELEZI, 2000). O desenho bidimensional em alto-relevo apresentou-se com pouca possibilidade de reconhecimento e distinção entreas figuras de corpo humano para os sujei tos quenunca enxergaram. Dessa forma, pode-setraçar um perfil das principais dificuldades dos sujeitos que não enxergam para identificar estetipo de material, dentreelas, destaca-sea pouca prática na vivência destes com desenhos: "P ra gente que é cego congênito, por não ter sido adaptado a ver desenho desde o início, é muito difícil a gente identificar" relata a participante4. "A gora vocêmepegou numa coisa, assim, queeu costumo dizer que desenhos em figuras para o cego, el e não tem muito efeito, ta!" enfatiza a participante 10.

Uma outra dificuldade encontrada diz respeito à visão sequencial própria do indivíduo que enxerga com a mão. O desenho grafo-tátil dificulta a maneira específica do sujeito com cegueira "ver" o mundo, por meio da esfera tátil: "N a verdade, quem enxerga, ol ha assim evêtodos de uma vez, né. $Q$ uando a gente vê o último, a gentejá esqueceu quasequeo primeiro." (p5). Asquantidades deinformações presentes na ESB associada com a dificuldade de reconhecimento impedem que a pessoa com cegueira possua uma percepção global da Escala, necessária para o processo de comparação de uma figura com a outra.

A demais, a vivência e a prática com a linguagem grafo-tátil são fundamentais para o processo de reconhecimento dos desenhos representados na ESB. Todavia, uma dificuldade adicional para a identificação da Escala foi que esta linguagem, para a confecção de desenhos, ainda é um método de adaptação pouco atraente aos participantes desteestudo: “N unca gostei de desen ho, a professora me dava aula, mas eu não ligava. Tentar reconhecer, às vezes, eu tentava, mas eu tinha muita dificuldade de reconhecer um desenho. A té hoje, eu tenho essa dificuldade." (p.20).

Mesmo frente às dificuldades relatadas pelos participantes, que os impossibilitaram de reconhecer a ESB, a linguagem grafo-tátil teve um espaço privilegiado em al gumas dimensões. Esse tipo de comunicação da pessoa que não enxerga com o mundo deve ser considerada uma possibilidade de adaptação em outros campos do conhecimento, como na confecção de materiais adaptados que privilegiem a Matemática, a Física, entre outras disciplinas no processo de ensino eaprendizagem. Para os próprios sujeitos com cegueira, a linguagem bidimensional é considerada uma relevante fonte de informações para a formação de algumas imagens mentais, como afirma a participante 4: "A gente consegue identificar figuras geométricas, né, porque a gente começou a ser iniciado nisso, nessa parte de pirâmide [...] 0 gráfico é muito interessante para o cego nesse aspecto".

Valelembrar quea vivência com a linguagem grafo-tátil éfundamental para o processo de reconhecimento das figuras. Atualmente, a divulgação de material grafo-tátil está concentrada, sobretudo, na adaptação de figuras geométricas, mapas, esquemas de célula, entre outras: “É, eu já vi, porque veio pra nós deSão Paulo o mapa mundi eo mapa regional. Eu já conheci M inas Gerais no mapa, eu 
brinco que M inas tem um nariz comprido" (p19). No entanto, há uma lacuna de materiais grafo-táteis que representem o corpo humano, o que pode ser um fator preponderante para a justificativa quea maioria dos participantes relatou denunca ter visto os desenhos da ESB.

Outra utilidade apontada pelos participantes relaciona-se com a possi bilidadeaumentada deestimulação tátil através dos desenhos bidimensionais, como consta no seguinte relato: "É porque isso obriga a pessoa a forçar o tato, a mente, isso é muito bom!" (P5). Ou ainda no relato de uma professora com cegueira que estimula seus alunos a praticarem a identificação de desenhos:

\footnotetext{
Eu gosto muito, mas dificilmente eu já tive aluno que interessasse pelo desenho, eles querem logo ir aprendendo a ler e a escrever, mas eu sempre disse que o importante é primeiro o tato, porquea gente não tem o tato pronto, a gente vai adquirindo na medida que a gente vai usando ele, então, eu sempre peço aos meus alunos para procurarem tatear tudo que eles puderem ( $p 19$ ).
}

Nesse contexto, pode-se inferir que as utilidades do desenho grafotátil referem-se não somente a figuras geométricas, mapas e esquemas utilizados usualmenteno processo deensino eaprendizagem, mas, sobretudo, à possibilidade de estimulação tátil, que irá acompanhar o sujeito que não enxerga durante toda sua existência.

Todavia, no que diz respeito aos desenhos da ESB, a linguagem grafotátil bidimensional não é a mais adequada, visto que a maioria (90\%) dos partici pantes deste estudo não reconheceu de imediato a referida Escala, logo, esta não deve ser utilizada com a pretensão de avaliar o componente atitudinal da imagem corporal. Os participantes não identificaram corpos humanos nos desenhos e, muito menos, as diferenças no corpo dos bonecos, o que compromete a aplicabilidadeda Escala ao público com deficiência visual. O mesmo não aconteceu com a EST, como descrito a seguir.

\section{Escala de Silhuetas Tridimensionais}

A linguagem tridimensional pode ser equiparada à realidade propriamente dita, tendo em vista que esta é tridimensional. Ao pegar um brinquedo, uma boneca, ou a figura de um santo, o sujeito que não enxerga já vivencia e experimenta sensações que podem possi bilitá-lo formar imagens mentais de corpo. Dessa forma, a EST possibilitou aos participantes um resgate de seus conhecimentos anteriores para a identificação e reconhecimento da Escala, como consta na formação de 3 subcategorias:

a) Reconhecimento da Escala: refere-se às justificativas que esclarecem a identificação de diferentes características dos bonecos, sobretudo, à associação com formas humanas e as diferenças corporais. 
b) Relação consigo ou com o outro: refere-se à síntese de associações dos modelos da EST com o próprio sujeito ou com outra pessoa, que confirmam o reconhecimentos da Escala.

c) Facilidades e preferências da EST: refere-se aos depoimentos que privilegiam sobremaneira a adaptação da Escala em forma tridimensional em detrimento da adaptação bidimensional.

Foram extensos os depoimentos que constataram o reconhecimento da Escala de Silhuetas Tridimensionais pelos participantes. Todos reconheceram as diferentes dimensões e formas corporais representadas na ESB, em um tempo quase que de imediato ao toque. Eles foram enfáticos ao relatarem as diferenças corporais dos bonecos, mostrando propriedade na identificação deste tipo de material, como afirmam os seguintes participantes: "U ns bonecos! São outras pessoas. São nove também? São gordos, uns bem gordos! [...] e outros são mais magros" (p2). "A diferença é no tamanho, a primeira é a menorzinha, a última éa maior. A altura é tudo a mesma coisa, a única diferença é que umas são mais magras, outras são mais gordas" (p3). “Bom, isso aqui são corpos. [...] U m é mais gordo do que o outro. [...] Q uanto mais pra cá, mais gordos eles são" (p4). Alguns participantes foram detal histas na descrição dos modelos da Escala, como segue:

\footnotetext{
Isso aqui é um humano! [...] Tem as costas, eu não sei se ele é magro ou se ele é mais definido nas costas, mas é mais provável que ele seja... D eixa eu ver aqui... É mais provável que ele seja magro, porque se ele fosse definido nas costas ele teria definição também na frente, então, aqui, ó, ele é magro, porque esses ossos daqui, ó, eu esqueci o nome desse osso aqui de trás, eu não sei se é omoplata, sei lá. [...] (p5).
}

Fica evidente, então, que o modelo de silhuetas humanas representado de forma tridimensional traz ao sujeito que não enxerga um precioso conjunto de informações sobre o corpo, que possibilita a formação de imagens mentais. Estas imagens poderiam estar, até então, confusas e codificadas, visto que há poucos materiais adaptados que representem diferentes formas corporais. Destaca-se que nos inúmeros depoimentos, os participantes relacionaram os model os consigo, com o outro ou com coisas, o que confirma que a EST possibilita um resgate e uma concretização de imagens mentais anteriormente formuladas. A participante 3 associou o modelo $1 \mathrm{daEST}$ com uma imagem de uma pessoa anoréxica, como consta: "A primeira é aquela magricela mesmo, aquela... como é que se diz? A quela 'neuréxica'" [sic]. Já a participante 15 associou o modelo 1 com al guém desnutrido: "A qui é uma pessoa que tá tão magra, que ela tá além. Bonita, né? A s curvas tudo, mas ela tá tão além de, como se diz lá na pastoral da criança, a gente chamava isso de desnutrida [sic]."

Para fazer referências às pessoas gordas, algumas associações foram empregadas, mostrando um aprimorado reconhecimento dos modelos, como afirma o participante 5: "A h, esse cara aqui é lutador de sumô (risos). Cara, eu considero esse cara gordo! N em forte! Já passou de forte, porque ol ha só, a barriga dele, cara, está até um pou co mais al ta do que o short dele". A lém do lutador de sumô, o rei Momo aparece 
no depoimento do mesmo participante como uma forma de expressar seus sentimentos quanto ao boneco 9:

Esse aqui é gordo, né, cara! Esse aqui éum rei $M$ omo! (risos). [...] Q ueisso! Esse aqui acho que não consegue nem se levantar mais! [...] Estou averiguando dois pneus, de trator. Cara, ol ha as gorduras dele, mórbidas, tudo aqui, ó. Olha, o pescoço aqui, ó, cheio de gordura! (p5).

Fica evidente a riqueza de detal hes queapareceno depoimento relatado anteriormente quanto às características dos bonecos mais gordos. Dessa maneira, pode-se inferir que a EST traz à pessoa com cegueira detal hes importantes para a distinção de um modelo do outro, assim como de uma forma corporal da outra. Além disso, ela permite outros tipos de associações, como a identificação de um boneco que se pareça com um vizinho: "Essa aqui, nossa mãe! Essa aqui émeu vizinho (risos)" (p15), ou com um colega: "M ais gordo ainda, peso pesado, pesadíssimo! Parece até com um colega meu esse aqui..." (p8). No entanto, o que é mais relevante neste estudo é a relação que os participantes fizeram dos bonecos consigo.

A referida relação comprova queaEST poderia ser aplicável nos estudos que avaliam o componente atitudinal da imagem corporal, já que fica constatado queos deficientes conseguem perceber, nos model os adaptados, al gum semel hante ao próprio corpo, como afirmam, por exemplo, os participantes 7, 12, 14 e 16, respectivamente: "E sse aqui eu acho que já é um pouquinho mais forte do que eu sou"; "Esse aqui é igual eu, porque eu já engordei um pouquinho também, né"; "Ih, esse aqui é bem fininho, parecido comigo"; "Porque esse aqui el e não é muito pequeno, mas também não é muito gran de e tá magro igual eu, digo, assim, o corpo dele, é assim igual ao meu" . Tal constatação érelevante para estudos futuros que visem investigar as qualidades psicométricas da EST.

Outra constatação importante para estudos futuros é que a linguagem tridimensional é mais adequada para adaptação de materiais às pessoas com deficiência visual congênita, segundo a própria interpretação delas. Ela possi bilita facilidades que, em outros tipos de adaptação, como a linguagem bidimensional, não existem. Dentre estas facilidades destacam-se a riqueza de detalhes da EST, sem que estes confundam a pessoa com cegueira no processo de identificação, como afirma o participante 7: " [...] me dá os detal hes aí do rosto, nariz, boca, ol hos, as alturinhas, né? Eu vejo até as alturinhas das sobrancelhas. [...] Q uanto mais detalhes é melhor, muito melhor o de gesso". Uma outra facilidade relatada é a característica tridimensional da EST que permite noções de profundidade e multidimensionalidade, próprias do corpo humano: "Esse desenho aqui é bem mais prático para o cego poder identificar, entendeu? Porque el é 3D, vocêconsegue identificar a profundidade do desenho, coisa que o cego não consegue no papel por si só (p4)".

A lém desta, as experiências anteriores dos partici pantes com model os tridimensionais permitiu quehouvessecerta facilidadeno processo deidentificação e reconhecimento dos modelos. A vivência e experimentação de bonecos e santos 
possibilitaram um reconhecimento satisfatório dos modelos, como afirma o participante 16: “Em al guns lugares quea gentevai, já tem figuras parecidas, tipo imagem de santo, se assemel ha mais com esse daqui..." ou a participante 19:

A gora, aqui, eu já fui ol hando, assim, fica parecido com al guma boneca, né? A boneca a gente conhece, assim, de pegar. Eu tive boneca, eu vejo criança que tem boneca, eu ponho a mão, assim, percebo que fica parecido com o corpo humano.

Por fim, uma outra facilidade importante relatada pelos participantes diz respeito a autonomia que a EST proporciona no processo de identificação das figuras. Ao contrário da linguagem bidimensional, que precisaria de um intermediador entre os desenhos e a pessoa com cegueira, com a finalidade de explicar com detal hes o quesignificam erepresentam os desenhos bidimensionais, a comuni cação via mensagem tridimensional, característica daEST, possi bilita que o sujeito que não enxerga consiga decodificar, sozinho, as nuances das figuras, em um tempo quase que de imediato ao toque, como afirma o participante 10:

\footnotetext{
$\{. .$.$] o desenho matemático, escrito em altorrelevo, tem quealguém orientar na primeira$ vez, pra gente poder ir perceben do o que que é. A gora, é difer ente de você pegar um de gesso, igual esse aqui, porque vocêpega aqui e de imediato, vocêjá vai saber com o que ele parece. $\mathrm{N}$ ão precisa de orientação.
}

A aplicação do instrumento deavaliação deum componenteda imagem corporal para o público com cegueira que Ihe ofereça autonomia é um fator relevante, dado que as pesquisas contemporâneas que investigam este tema têm utilizado como principal instrumento deavaliação al gum tipo de entrevista, como as encontradas nos estudos de Delazari (2006) e Ferreira (2007), ou questionário, utilizado nos estudos de Pierce e Wardle (1996) e Baker, Sivyer e Towell (1998). Tais instrumentos são aplicados com o auxílio de um "ledor" que, normal mente, é o próprio pesquisador, o que restringi a possibilidade do sujeito que não enxerga de utilizar sua principal maneira de formular imagens das coisas e do mundo, 0 tato. Além disso, a exploração da EST pelos participantes deste estudo foi considerada uma tarefa fácil e estimulante, o que possibilita agilidade na identificação da Escala.

\section{Conclusões}

Ao longo deste estudo foram apresentadas as considerações, os sentimentos e as motivações singulares das pessoas com deficiência visual relacionados às duas Escal as deSil huetas exploradas, a bi ea tridimensional. Diante dos relatos colhidos nesta pesquisa, constata-se que a EST é mais adequada e representativa de diferentes dimensões e formas corporais para a pessoa com cegueira congênita do quea ESB. A EST pode possibilitar ao sujeito quenão enxerga descortinar, na ponta deseus dedos, tamanhos edimensões corporais diferenciadas, tornando possível a realização de estudos que investiguem a satisfação corporal 
deste público. Sugere-se a realização de pesquisas futuras que visem avaliar as qualidades psicométricas da EST.

\section{REFERÊNCIAS}

ALMEIDA, J. J. G. Estratégias para a apren dizagem esportiva: uma abordagem pedagógica da atividademotora para cegos e deficientes visuais. 176f. 1995. Tese(Doutorado em Educação) - Faculdade de Educação Física, Universidade Estadual de Campinas, Campinas, 1995.

CASH, T. F. A "N egativeBody Image": Evaluating Epidemiological Evidence. In: CASH,T. F., PRUZINSKY,T. Body Image: a handbook of theory, research \& clinical practice. N ova Iorque: Guilford Press, 2004, p. 269-276.

BAKER, D.; SIVYPER, R.; TOWELL, T. Body image dissatisfaction and eating attitudes in visually impaired women. International Journal of Eating D isorders, New York, v. 24, n. 3, p. 319-322, mar./ apr. 1998.

BA RDIN, L. A nálise de conteúdo. Trad. Luís A ntero Reto eA ugusto Pinheiro. Lisboa: Edições 70, 1977.

BATISTA, C. G. Formação de conceitos em crianças cegas: questões teóricas e implicações educacionais. Psicologia: Teoria e Pesquisa, Brasília, v. 21, n. 1, p. 7-15, jan./ abr. 2005.

DELAZARI, F. M. Cegueira e normatividade social : a reconstrução da subjetividade frente à perda tardia da visão. 157 f. 2006. Dissertação (Mestrado em Sociologia) - Universidade Federal do Paraná, Paraná, 2006.

DOLTO, F. A imagem inconsciente do corpo. São Paulo: Perspectiva, 2001.

DOLTO, F.; NASIO, J. D. A criança do espelho. Trad. André Telles. Rio de Janeiro: Jorge Zahar, 2008.

FERREIRA M.E. C. Imagem corporal, autoestima evaidade sob a per spectiva de deficientes visuais congênitos. 2007. 195 f. Tese (Pós-Doutorado em Educação) - Faculdade de Educação, Universidade de São Paulo, São Paulo, 2007.

GARNER, D. M.; GARFIN KEL, P. E. Body image in anorexia nervosa: Measurement theory and clinical implications, International Journal of Psychiatry and M edicine. v. 11, n. 3, p. 263 284, 1981.

GEERTZ, Clifford. A interpretação das culturas. Rio de Janeiro: Guanabara, 1989.

JACKSON, L. A. Physical Attractiveness: a Sociocultural Perspective. In: CASH,T., PRUZIN SKY,T. Body I mage: a handbook of theory, research \& clinical practice. N ova I orque: Guilford Press, 2004.

KRUEGER, D. W. Psychodynamic Perspectives on Body Image. In: CASH, T., PRUZINSKY, T. B ody Image: a handbook of theory, research \& clinical practice. N ova lorque: Guilford Press, 2004, p. 30-37.

LAPLANE, A. L. F.; BATISTA, C. G. Um estudo das concepções de professores de ensino fundamental e médio sobre a aquisição de conceitos, aprendizagem e Deficiência Visual [Resumo]. In: CON GRESSO BRASI LEIRO DE EDUCAÇÃO ESPECIAL, 1; Ciclo de Estudos sobre Deficiência Mental, 9, 2003. A nais... São Paulo: UFSCar, 2003. 
LAPLANE, A. L. F.; BATISTA , C. G. V er, não ver eapren der: a partici pação de crianças com baixa visão e ceguei ra na escola. Cad. Cedes, Campinas, v. 28, n. 75, p. 209-227, maio/ ago. 2008.

LEMOS, É. R. Educação de excepcionais - evolução histórica desenvolvimento no Brasil. Niterói: UFF, 1981. Tese e Livre-Docência, 1981.

MALHOTRA, N. K. Pesquisa de marketing: uma orientação aplicada. 3. ed. Porto Alegre: Bookman, 2001.

MERLEAU-PONTY, M. 0 visível e o invisível. Trad. José Artur Gianotti e Armando Mora d'Oliveira. 4. ed. São Paulo: Perspectiva, 2007.

MORGADO, F. F. R. et al . A nálise dos Instrumentos de Avaliação da imagem corporal. Fitness and Performance J ournal, v. 8, p. 204-211, 2009.

MORGADO, F. F. R.; FERREIRA, M. E. C. A daptação deEscalas deSilhuetas Bidimensionais eTridimensionais para o deficiente visual. In: MORGADO, F.F.R. V alidação e confiabilidade de uma Escala de Silhuetas Tridimensionais para o cego congênito. 2009. 119 f. Dissertação (M estrado em Educação Física) - Faculdade de Educação Física, Universidade Federal de Juiz deFora, Minas Gerais, 2009.

NUNES, S. S. D esenvolvimento de conceitos em cegos congênitos: caminhos de aquisição do conhecimento. 2004. 287 f. Dissertação (M estrado em Psicologia) - Instituto de Psi cologia, Universidade de São Paulo, São Paulo, 2004.

ORMELEZI, E. M. Os caminhos da aquisição do conhecimento e a cegueira: do universo do corpo ao universo simbólico. 2000. 273f. Dissertação (M estrado em Psicologia e Educação) - Faculdade de Educação, Universidade de São Paulo, São Paulo, 2000.

PIERCE, W. J; WARDLE J. Body size, parental appraisal, and self-esteem in blind children. Journal of Child Psychology and Psychiatry, London, v. 37, n. 2, p. 205-212, mar. 1996.

PREISLER, G. Social and emotional development of blind children: a longitudinal study. In: LEWIS, V.; COLLIS, G.M. (Org.). Blindness and psychological devel opment in young children. Londres: The British Psychological Society, 1997. p. 69-85.

SAMPIERI, R. H.; COLLADO, C. F.; LUCIO, P. B. M etodologia de la investigación. México: McGraw-Hill, 1991.

SCHILDER, P. A imagem do corpo: as energias construtivas da psique. 3. ed. São Paulo: Martins Fontes, 1999.

STUNKARD A. J.; SOREN SEN T.; SCHLUSIN GER F. Useof theDanish A doption Register for thestudy of obesity and thinness. In: Kety SS, Rowland LP, Sidman RL, MatthysseSW, editors. The genetics of neurol ogical and psychiatric disorders. New York: Raven, p. 115-20, 1983.

TAVA RES, M. C. G. C. I magem corporal: conceito edesenvolvimento. Barueri: Manole, 2003.

Recebido: 19/ 08/ 2009

Reformulado: 12/11/ 2010

A provado: 05/ 03/ 2010 